\title{
Plasma and synovial fluid as solvents for monosodium urate
}

\author{
ROBERT W. DORNER, TERRY D. WEISS, ANDREW R. BALDASSARE, \\ TERRY L. MOORE, AND JACK ZUCKNER
}

From the Division of Rheumatology, Saint Louis University School of Medicine, 1402 South Grand Boulevard, Saint Louis, Missouri 63104, USA

SUMMARY In-vitro differences in monosodium urate (MSU) crystal dissolution in paired plasma and synovial fluid samples from patients with various arthritides were studied. Plasma was a significantly better solvent for MSU than synovial fluid (overall difference $6 \cdot 3 \mathrm{mg} / \mathrm{dl}(0 \cdot 37 \mathrm{mmol} / \mathrm{l})$; significant at $\mathrm{P}<0 \cdot 001)$. Attempts to correlate the solubility differentials with the principal compositional differences between the 2 fluids were only partially successful. (1) A tendency towards higher MSU solubility at higher protein levels was observed, but it was too slight to reach statistical significance. (2) Hyaluronidase treatment of synovial fluid significantly enhanced its ability to dissolve MSU (overall difference $2.2 \mathrm{mg} / \mathrm{dl}(0.13 \mathrm{mmol} / \mathrm{l})$; significant at $\mathrm{P}<0.01)$ but not sufficiently to explain wholly the plasma-synovial fluid differential.

Monosodium urate (MSU) microcrystals in synovial fluid play a central role in current schemes of pathogenesis of the acute gouty attack..$^{1-4}$ However, the reason for selective deposition of MSU in synovial fluid and other connective tissues is still poorly understood. In the present investigation we studied the amounts of MSU which can be dissolved in an in-vitro system with paired samples of plasma and synovial fluid from patients with various arthritides. Attempts were made to correlate the observed differences with the known principal compositional differences between plasma and synovial fluid, namely, those in total protein and hyaluronate.

\section{Materials and methods}

Blood and synovial fluid collected in heparinised tubes were obtained from patients at St Louis University Hospitals and Arthritis Clinic and at the office of collaborating physicians. Cells and debris were removed from synovial fluid by centrifugation at $1000 \mathrm{~g}$ for $20 \mathrm{~min}$. Only the top two-thirds of the fluid were used. Plasma and synovial fluid samples were stored at $-20^{\circ} \mathrm{C}$ prior to use.

Monosodium urate dihydrate microcrystals were prepared according to McCarty and Faires. ${ }^{5}$ All the experiments were performed with MSU from a single

Accepted for publication 7 January 1980. Correspondence to Dr Robert W. Dorner. batch. Aliquots of $10 \mathrm{mg}$ were sterilised by auto claving and incubated at $37^{\circ} \mathrm{C}$ with $4 \mathrm{ml}$ of plasma? or synovial fluid in a $25 \mathrm{~mm}$ outer diameter test tube containing a Teflon-covered stirring bar (autoclaved separately). Incubation was carried out by suspending 4 of the test-tubes near the centre of a 1 liter beaker through which a rapid flow of water from a circulating water bath was running and which was positioned on a magnetic stirrer, adjusted to provide vigorous stirring in the test-tubes. Preliminary studies with both plasma and synovial fluid showed that very large amounts of MSU dissolved during the first 2 hours of incubation, but that much of the originally dissolved MSU was precipitated again during the subsequent 2 hours. A steady state was reached after about 8 hours. All of our studies were done in a 16-hour incubation period. Undissolved MSU was removed by filtration through $0.65 \mathrm{~nm}$ Millipore membranes with a preheated Gelman centrifugal filter holder and a table top centrifuge at $1000 \mathrm{~g}$ for 3 minutes. Paired samples were always processed simultaneously to preclude experimental variations. Each filtrate was examined by polarised light microscopy to confirm the adequacy of the filtration procedure.

MSU in the filtrates was assayed by a uricase method, ${ }^{6}$ total protein by the Lowry method. ${ }^{7}$ Treatment of synovial fluid with bovine testicular hyaluronidase (Sigma Chemical Co., St Louis, MO, USA) was done according to a previously described 
method $^{8}$ which employs a lyophilised hyalurinidasebuffer mixture to avoid sample dilution. However, sterile tubes were used and the hyaluronidase-buffer solution was sterilised by Millipore filtration prior to lyophilisation. Control tubes containing only lyophilised buffer were prepared similarly. Hyaluronidase-treated and control samples were then subjected to MSU solubility studies as described above. Preliminary experiments confirmed the efficacy of hyaluronidase treatment by viscosimetry as previously described. ${ }^{8}$

To test the reproducibility of these procedures aliquots of a plasma sample from a healthy volunteer and aliquots of a synovial fluid pool from patients with large effusions were subjected to urate solubility determination on 5 separate occasions by the procedures outlined above. The mean dissolved urate in plasma was $8.2 \mathrm{mg} / \mathrm{dl}(0.49 \mathrm{mmol} / \mathrm{l})$ with a standard deviation of $0.43(0.026)$ or $5 \%$. Corresponding values for synovial fluid were $7 \cdot 8$ $(0.46), 0.31(0.002)$ or $4 \%$ respectively. For comparison the uricase method itself in our hands gives replications with a standard deviation of about $3 \%$ around the mean. Presumably similar confidence limits are applicable to the data obtained on the experimental samples which were not available in sufficient quantities to permit multiple determinations.

\section{Results}

The amounts of MSU dissolved in paired samples of plasma and synovial fluid from 32 patients with various arthritides under standardised conditions are shown graphically in Fig. 1. The data have bsen separated according to the primary diagnosis of the donor of the samples. Under the heading 'Other' patients with inflammatory arthropathies other than rheumatoid arthritis or gout were included. None of them had infectious arthritis. The data show that plasma (left-hand column in each category) was almost always a better solvent for MSU than synovial fluid (right-hand column in each category). The mean differences as well as the statistical significance limits by $t$ test for paired samples, are shown in Table 1. All the mean differences were statistically significant as usually defined at the $95 \%$ confidence limit. Patients with gout showed a lesser mean difference and a lower confldence limit than the overall mean, while patients with osteoarthritis showed the largest mean difference.

An attempt was made to explain the solubility differentials between plasma and synovial fluid on the basis of differences in total protein content. Fig. 2 is a scatter plot relating MSU solubility to total protein concentration of plasma and synovial fluid.
The correlation lines were obtained by least-squares fitting of the experimental points. The correlation coefficient for synovial fluid only was $r=0 \cdot 265$ (no significant correlation), that for plasma only $r=0.056$ (no significant correlation), and that for all data combined $\mathrm{r}=0.364$ (significant at the 0.01 confidence level). The latter observation is not meaningful in the absence of significant correlations in the 2 subgroups.

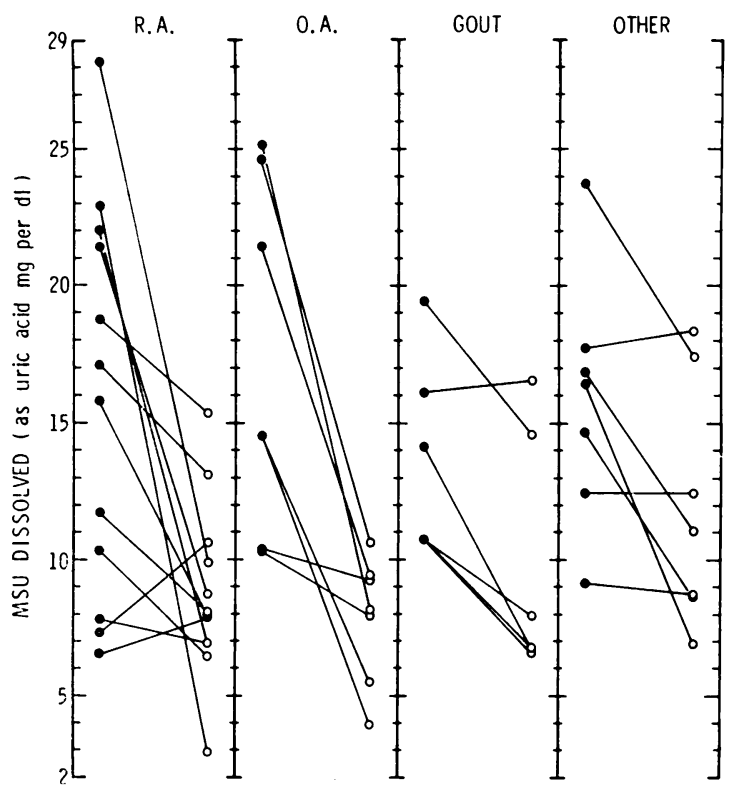

Fig. 1 Amounts of $M S U$ dissolved in paired samples of plasma and synovial fluid under standardised in vitro conditions. The data are separated according to diagnosis: $R A=$ rheumatoid arthritis; $O A=$ osteoarthritis; other =other inflammatory arthritides. In each disease category the left-hand column (•) represents plasma urate levels, the right-hand column (O) synovial fluid urate levels. Members of a pair are connected with a line. SI conversion: Urate mmol/l= $m g / d l \times 0.0595$.

Table 1 Mean differences of the amount of $M S U$ dissolved in plasma and in synovial fluid (paired samples) from patients with various arthritides

\begin{tabular}{llll}
\hline $\begin{array}{l}\text { Number } \\
\text { of } \\
\text { specimens }\end{array}$ & Diagnosis & $\begin{array}{l}\text { Mean } \\
\text { difference } \\
(m g \text { per } d l)\end{array}$ & $\begin{array}{l}\text { Statistical } \\
\text { significance } \\
\text { (P less than }\end{array}$ \\
\hline 12 & Rheumatoid arthritis & 7.1 & 0.01 \\
7 & Osteoarthritis & 9.5 & 0.01 \\
6 & Gout & 3.8 & 0.02 \\
7 & $\begin{array}{l}\text { Other inflammatory } \\
\text { arthropathies }\end{array}$ & 3.9 & 0.05 \\
32 & All patients combined & 6.2 & 0.001 \\
\hline
\end{tabular}

SI conversion: Urate $\mathrm{mmol} / \mathrm{l}=\mathrm{mg} / \mathrm{dl} \times \mathbf{0 . 0 5 9 5}$. 


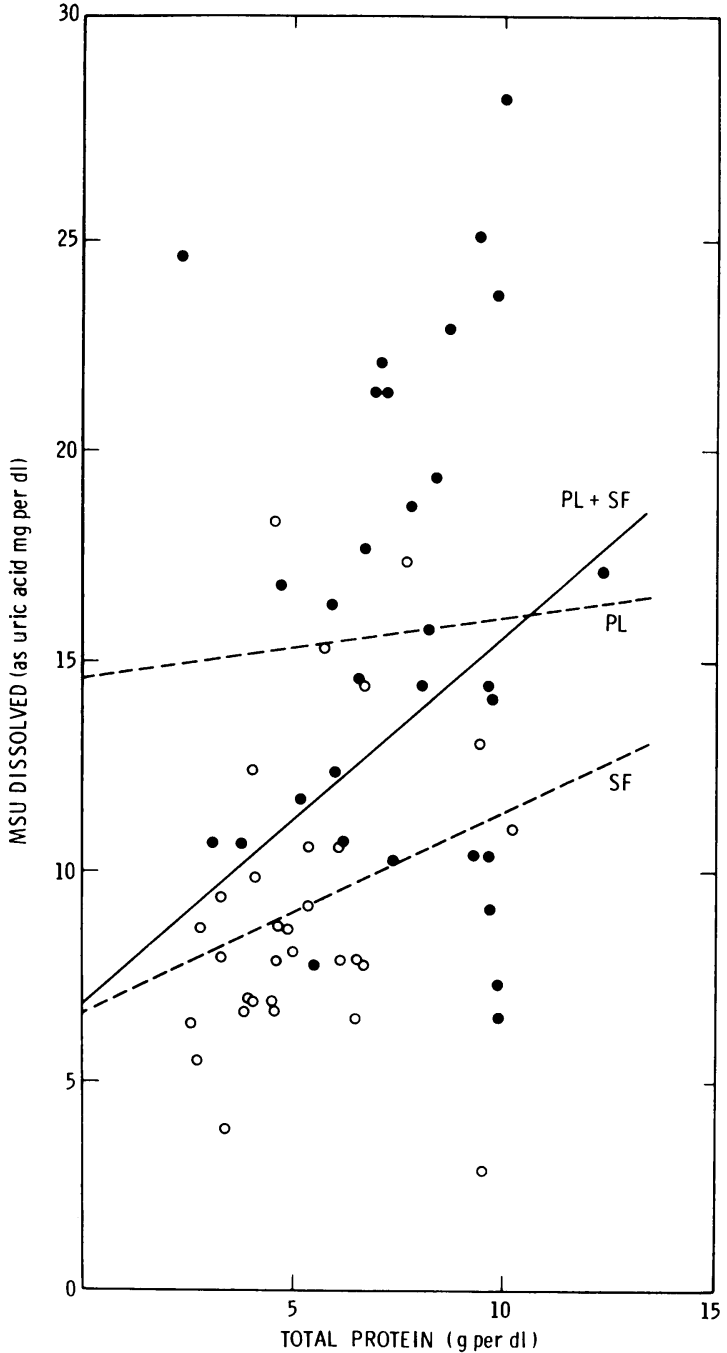

Fig. 2 Relation of MSU solubility to total protein concentration. The graph represents a scatter plot relating the quantity of MSU dissolved in plasma (•) or synovial fluid $(\mathrm{O})$ under standardised in-vitro conditions to the total protein concentration of the solvent. The correlation lines were obtained by leastsquares fitting. $P L$ - plasma; $S F-$ synovial fluid, $P L+$ $S F=$ all data combined. $S I$ conversion: Urate $\mathrm{mmol} / \mathrm{l}=$ $m g / d l \times 0.0595$; protein $g / l=g / d l \times 10$.

The amounts of MSU dissolved in hyaluronidasetreated and control synovial fluids from patients with various arthritides are shown graphically in Fig. 3. Again the data have been separated according to diagnosis. They show that in most cases hyaluronidase-treated synovial fluid is a better solvent for MSU than buffered control fluid. The mean

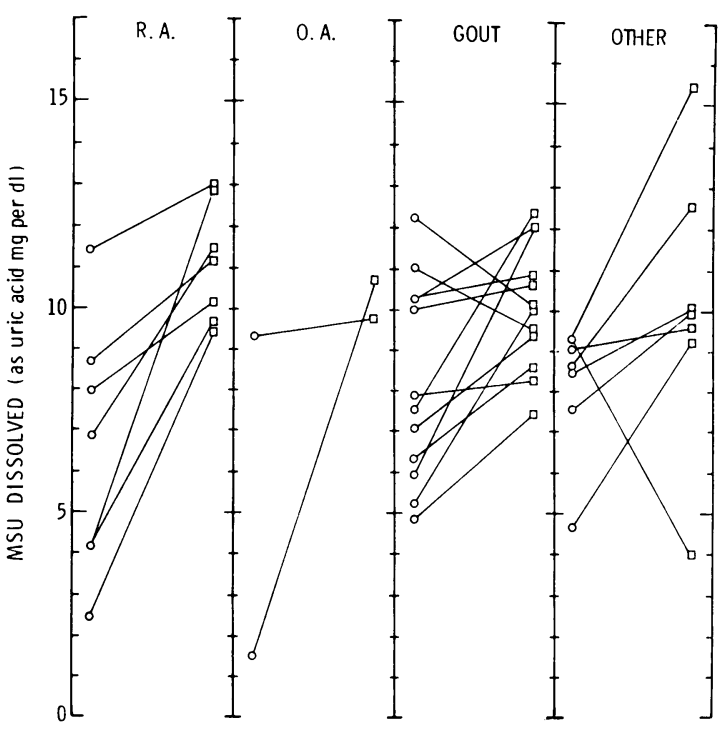

Fig. 3 Amounts of MSU dissolved in hyaluronidasetreated and control synovial fluids. The data are separated according to diagnosis (see legend to Fig. 1). In each disease category the left-hand column (O) represents urate levels of synovial fluid treated with buffer only $\left.\left(37^{\circ} \mathrm{C}\right), 4 \mathrm{hr}\right)$, the right-hand column $(\square)$ those after hyaluronidase treatment under the same conditions, prior to MSU solubility studies under standardised conditions. Corresponding hyaluronidasetreated and control samples are connected with a line. SI conversion: Urate $\mathrm{mmol} / \mathrm{l}=\mathrm{mg} / \mathrm{dl} \times 0.0595$.

differences, as well as their statistical significance by $t$ test for paired samples are shown in Table 2 . The overall mean difference for all patients was significant at the $99 \%$ confidence limit. Significant differences were also found for the patients with rheumatoid arthritis and those with gout, while the difference for patients with other inflammatory arthritides was not significant. The number of osteoarthritis patients included was too small to permit meaningful statistical analysis.

Table 2 Mean differences of the amounts of $M S U$ dissolved in hyaluronidase-treated and control synovial fluid (paired samples) from patients with various arthritides

\begin{tabular}{llll}
\hline $\begin{array}{l}\text { Number } \\
\text { of } \\
\text { specimens }\end{array}$ & Diagnosis & $\begin{array}{l}\text { Mean } \\
\text { difference } \\
(\mathrm{mg} \text { per } d l)\end{array}$ & $\begin{array}{l}\text { Statistical } \\
\text { significance } \\
(P \text { less than })\end{array}$ \\
\hline 7 & Rheumatoid arthritis & $4 \cdot 2$ & $0 \cdot 01$ \\
12 & Gout & $1 \cdot 9$ & $0 \cdot 05$ \\
2 & Osteoarthritis & $4 \cdot 8$ & - \\
7 & $\begin{array}{l}\text { Other inflammatory } \\
\text { arthropathies }\end{array}$ & $2 \cdot 0$ & not significant \\
28 & All patients combined & $2 \cdot 2$ & $0 \cdot 01$ \\
\hline
\end{tabular}

SI conversion: Urate $\mathrm{mmol} / \mathrm{l}=\mathrm{mg} / \mathrm{dl} \times 0.0595$. 


\section{Discussion}

MSU crystals found in synovial fluid and other connective tissues of patients with gout form an important aspect of all accounts of pathogenesis of the acute gouty attack. ${ }^{1-4}$ However, why MSU should be selectively deposited in these tissues is not fully understood. Explanations involving the $\mathrm{pH}$ differential between plasma and the synovial fluid in an involved joint have been discredited.49 Temperature differentials between joint spaces and the systemic circulation exist ${ }^{10}$ and have been considered as a possible cause of MSU crystal deposition. ${ }^{11}$ Urate-binding proteins ${ }^{12}{ }^{13}$ and protein-polysaccharides ${ }^{14} 15$ have been described, but their significance is not clear.

We have undertaken to study in vitro the ability of plasma and synovial fluid, obtained simultaneously from patients with various arthritides, to dissolve microcrystalline MSU. Our data show that plasma is a better solvent for MSU than synovial fluid. The differential may be sufficient to explain crystallisation of MSU in synovial fluid at urate levels which do not exceed the solubility in plasma. It can be estimated from published data $^{2} 10$ that this differential is greater by a factor of 3 than the solubility differential due only to temperature differences between joints and blood. Both factors may be of importance. Once local supersaturation exists, the phenomenon of nucleation ${ }^{16}$ is of great importance in the actual crystallisation process.

Normal synovial fluid has frequently been likened to an ultrafiltrate of plasma. Grossly, there are 2 principal differences between the 2 fluids. ${ }^{17}$ (i) Synovial fluid has less than half as much total protein as plasma; (ii) synovial fluid contains about $0.3 \%$ hyaluronate while plasma contains no more than traces. We explored the possibility that the solubility differences of MSU in plasma and synovial fluid might be related to these gross compositional differences.

A good case can be made for the influence of protein concentration on urate solubility, since Klinenberg and his associates ${ }^{2}$ have already shown that increasing concentrations of albumin enhance urate solubility proportionately. Our attempts at correlating MSU solubility with total protein concentration in plasma and synovial fluid showed a tendency toward increased solubility at higher protein concentration, but the correlation did not reach statistical significance.

The influence of high molecular weight hyaluronate has been explored by comparing hyaluronidase-treated and control samples of synovial fluid. Hyaluronidase treatment was found to enhance the ability of synovial fluid to dissolve MSU.
Since the patient populations used in comparing plasma versus synovial fluid and hyaluronidasetreated versus control synovial fluids were not the same, it is not possible to decide unequivocally whether the presence of highly polymerised hyaluronate in synovial fluid is sufficient to account for the differential in MSU solubility between plasma and synovial fluid. It appears that only about half the plasma versus synovial fluid differential can be explained by the effect of hyaluronate. The possibility that low molecular weight fragments of hyaluronate might have an effect on urate solubility has not been excluded. The data presented are hard to reconcile with the work of $\mathrm{Katz},{ }^{15}$ who found a urate-solubilising proteoglycan which is destroyed by hyaluronidase in synovial fluid. Our data are compatible with Laurent's ${ }^{18}$ excluded space concept, but the observed solubility differential is greater than what one might have predicted on the basis of Laurent's data.

Since MSU solubility is specifically a problem in patients with gout, it was of interest to compare the results obtained on samples from gouty patients with those from patients with other forms of arthritis. One might have expected the solubility differential between plasma and synovial fluid to be particularly large in patients with gout. This was not found to be true. The mean solubility differential for gouty patients was lower than that found in most other diseases. Similarly, the solubility change after hyaluronidase digestion was smaller than average; in fact 2 of the 3 synovial fluids in which hyaluronidase treatment did not enhance MSU solubility were from patients with gout. The significance of these findings is not clear at present.

We thank Mrs Claudia Barnes Cuca for the carefully executed technical work.

\section{References}

1 Seegmiller J E. The acute attack in gouty arthritis. Arthritis Rheum 1965; 8: 714-23.

2 Klinenberg J R, Bluestone R, Schlosstein L, Waisman J, Whitehouse $M$ W. Urate deposition disease. How is it regulated and how can it be modified? Ann Intern Med 1973; 78: 99-111.

8 McCarty J D, Kozin F. (1975). An overview of cellular and molecular mechanisms in crystal-induced inflammation. Arthritis Rheum 1975; 18: 757-64.

4 Spilberg I. Current concepts of the mechanism of acute inflammation in gouty arthritis. Arthritis Rheum 1975; 18: 219-34.

5 McCarty D J, Faires J S. A comparison of the duration of local anti-inflammatory effect of several adrenocorticosteroid esters - a bioassay technique. Curr Ther Res 1963; 5: 284-90.

6 Praetorius E, Poulson H. Enzymatic determination of uric acid. Scand J Clin Lab Invest 1953; 5: 273-80.

7 Lowry O H, Rosebrough N S, Farr A L, Randall R J. 
Protein measurement with the Folin phenol reagent. J Biol Chem 1951; 193: 265-75.

8 Dorner R W, Gantner G E, Uddin J, Zuckner J. The use of ultrasound in synovial fluid analysis. Arthritis Rheum $1965 ; 8: 368-75$.

9 Wilcox W R, Khalaf A, Weinberger A, Kippen I, Klinenberg J R. Solubility of uric acid and monosodium urate. Med Biol Eng 1972; 10: 522-31.

10 Horvath S M, Hollander J L. Intra-articular temperature as a measure of joint reaction. $J$ Clin Invest 1949; 28: 469-773.

11 Loeb J H. The influence of temperature on the solubility of monosodium urate. Arthritis Rheum 1972; 15: 189-92.

12 Alvsaker J O. Uric acid in human plasma. IV Investigations of the interaction between urate and macromolecular fractions from healthy individuals and patients with diseases associated with hyperuricemia. Scand $J$ Clin Lab Invest 1965; 17: 476-82.

13 Alvsaker J O. Uric acid in human plasma. V. Isolation and identification of plasma proteins interacting with urate. Scand J Clin Lab Invest 1966; 18: 227-39.

14 Katz W A, Schubert M. The interaction of monosodium urate with connective tissue components. $J$ Clin Invest 1970; 49: 1783-9.

15 Katz W A. Deposition of urate crystals in gout. Arthritis Rheum 1975; 18: 751-6.

16 Wilcox W R, Khalaf A A. Nucleation of monosodium urate crystals. Ann Rheum Dis 1975; 34: 332-9.

17 Hamerman D, Rosenberg L C, Schubert M. Diarthrodial joints revisited. J Bone Joint Surg 1970; 52A: 725-74.

18 Laurent T C. Solubility of sodium urate in presence of chondroitin-4-sulfate. Nature 1964; 202: 1334. 